\title{
Races of Phytophthora sojae in Arkansas Soybean Fields and Their Effects on Commonly Grown Soybean Cultivars
}

\author{
T. A. Jackson, former Graduate Research Assistant, Department of Plant Pathology, University of Arkansas, Fa- \\ yetteville 72701; T. L. Kirkpatrick, Professor, University of Arkansas, Southwest Research and Extension Center, \\ Hope 71801; and J. C. Rupe, Professor, Department of Plant Pathology, University of Arkansas, Fayetteville
}

\begin{abstract}
Jackson, T. A., Kirkpatrick, T. L., and Rupe, J. C. 2004. Races of Phytophthora sojae in Arkansas soybean fields and their effects on commonly grown soybean cultivars. Plant Dis. 88:345351.

Isolates of Phytophthora sojae were collected during 1995 to 1998 from soil samples collected in 23 Arkansas soybean fields in 14 counties, and characterized by race. A total of seven races (races 2, 10, 14, 15, 24, 26, and 38) were found. Races 10, 24, and 15 were the most common and comprised 47,22 , and $9 \%$ of the 32 isolates, respectively. A single isolate each of races 2 , 14,26 , and 38 also was found. Three of the isolates collected could not be characterized to race due to inconsistent results. In 1997 and 1998, a portion of a single soybean field at the University of Arkansas Southeast Research and Experiment Center near Rohwer, AR was surveyed intensively for $P$. sojae. The area was planted each year to the $P$. sojae-susceptible cv. Williams and both plants and soil were collected to assay for $P$. sojae from 16 and 28 plots ( 4.9 by $7.6 \mathrm{~m}$ ) in 1997 and 1998, respectively. A total of 83 isolates were collected (11 from plants and 72 from soil), and found to represent 13 pathotypes, including 6 with virulence formulae that have not been described previously. Nine commercial soybean cultivars representing a range of reported resistance and tolerance to Phytophthora root and stem rot were screened for resistance to races 10,15 , and 26 of $P$. sojae using both hypocotyl injection and inoculum layer techniques. Cvs. Manokin, Hartz Variety 5545, and Riverside 499 were consistently resistant to all of the races using both inoculation methods. These results indicate that, although considerable pathogenic variability in $P$. sojae exists in soybean fields in Arkansas, cultivars with effective resistance are available to help growers manage Phytophthora root and stem rot.
\end{abstract}

Phytophthora root and stem rot of soybean (Glycine max (L.) Merr.) is caused by Phytophthora sojae Kaufmann \& Gerdemann and is the second most serious soybean disease in the United States based on yield reduction (30). Average annual yield loss attributed to Phytophthora root and stem rot in the United States was estimated to be greater than $12 \times 10^{6}$ metric tons between 1996 and 1998 (30). The primary control measure for Phytophthora root and stem rot is the use of soybean cultivars with resistance genes (Rps genes). However, cultivar selection for the management of Phytophthora root and stem rot is complicated by the existence of races of the pathogen (21) and its ability to change relatively rapidly in response to selection pressure exerted by the continuous use of resistant cultivars $(1,10,23,26)$.

Currently, 55 races of $P$. sojae have been reported (20) based on their differential reaction on 8 to13 dominantly inherited resistance genes. These alleles have been

Corresponding author: T. L. Kirkpatrick

E-mail: tkirkpatrick@uaex.edu

Accepted for publication 7 October 2003.

Publication no. D-2004-0216-02R

(C) 2004 The American Phytopathological Society identified at seven different loci, with multiple alleles at some loci. Rps genes are used widely in commercial soybean cultivars for the control of Phytophthora root and stem rot $(23,26)$.

Effective deployment of Rps genes for management of Phytophthora root and stem rot requires a knowledge of the virulence formulae of local races of $P$. sojae. Race composition of the pathogen has been reported in several regions and, generally, one or two races predominate in an area, with several other races making up a smaller percentage of the total population studied. Groups of races with similar virulence formulae appear to be common regionally $(1,2,5,10,15,17,19,20,22,23,26,27$, 29,31 ), although a survey conducted by Barreto et al. (4) in Argentina found only race 1 .

Surveys within regions over time indicate that the frequency of occurrence of races of $P$. sojae may change after several years. Schmitthenner et al. (26) reported that races 3 (virulent on Rps 1 a and 7), 7 (Rps1a, 3a, 6, and 7), and 9 (Rps1a, 6 and, 7) were most prevalent from 1978 to 1980 in Ohio soybean fields. However, a subsequent survey conducted in the same area in 1990 revealed that races 1 (Rps 7$), 3,4$ (Rps1a, 1c, and 7), 7, and 8 (Rps1a, 1d, 6, and 7) were found most frequently (24). At least 34 additional pathotypes were identi- fied in a more recent survey conducted in Ohio in 1997 and 1999, indicating rapid changes in $P$. sojae diversity (7). Similar results were seen in the race composition of $P$. sojae in Australia, where only races 1 and 15 (Rps $3 \mathrm{a}$ and 7 ) were found prior to 1989 . Since then, however, race 4 has been identified in commercial fields and has become the predominant race (23). These results suggest that the races (pathotypes) and virulence formulae of $P$. sojae that occur within a region should be monitored on a regular basis in order to effectively deploy specific Rps genes for management of Phytophthora root and stem rot, and that sources of resistance should be changed frequently to lower selection pressure on the pathogen and minimize race shifts.

In Arkansas and many other soybeanproduction areas in the mid-southern United States, little is known about the variability of $P$. sojae in the state. In a survey conducted in Arkansas in 1977, race 3 was the only $P$. sojae race found statewide, except for a single isolate from the extreme southwestern corner of the state that was characterized as race 4 (H. J. Walters, personal communication). The identification of races 17 (Rps $1 \mathrm{~b}, 1 \mathrm{~d}, 3 \mathrm{a}, 6$, and 7) (15), 38 (Rps1a, 1b, 1c, 1d, 1k, 3a, 6, and 7), and 39 (Rps 1a, 1b, 1c, 3a, 6, and 7) (13) of $P$. sojae in the Mississippi River Delta area is an indication that the range of pathogenic variability of $P$. sojae in the region should be reevaluated.

The objectives of this research were to: collect and characterize isolates of $P$. sojae in commercial soybean fields in Arkansas, determine the degree of pathogenic variability that occurs within soybean fields, and determine whether currently available resistant cultivars that are adapted to the mid-southern United States are adequate for managing Phytophthora root and stem rot in the region.

\section{MATERIALS AND METHODS}

Field sampling. Soil samples were collected from 23 soybean fields in 14 Arkansas counties during the 1995, 1996, 1997, and 1998 growing seasons. Fields were identified for sampling based on the presence of stem-rotting symptoms of Phytophthora root and stem rot. At least five individual samples were taken arbitrarily to a depth of $15 \mathrm{~cm}$ using a hand trowel from the most severely affected areas of each field, and samples were bulked to 
represent a single composite sample for each field, with a final volume of approximately 1 liter.

In addition to commercial soybean fields, a portion of a soybean field at the Southeast Research and Extension Center (SEREC) near Rohwer, AR was sampled intensively to estimate the pathogenic variability of $P$. sojae within a single field. The field had a history of Phytophthora root and stem rot and had been used for several consecutive seasons for soybean cultivar yield performance evaluations. In both 1997 and 1998, the field was planted with the Phytophthora root and stem rotsusceptible cv. Williams and floodirrigated for $24 \mathrm{~h}$ at emergence to initiate disease development.

In 1997 , a $595-\mathrm{m}^{2}$ section ( 19.5 by 30.5 $\mathrm{m}$ ) of the field was divided into 16 plots of $37.2 \mathrm{~m}^{2}$ ( 4.9 by $7.6 \mathrm{~m}$ ) each, and soil samples were collected as described previously with a subsample taken from the corners and from the center of each plot. The five individual subsamples were bulked to form a composite sample of approximately 1 liter to represent each plot. In addition to the soil, 10 to 12 plants were collected at each sample date from each plot. Symptomatic plants were selected when they were available; otherwise, plants were selected arbitrarily from across each plot. Soil samples were taken once during each season at 3 weeks after planting. Plant samples were taken at 3 weeks after planting and again 6 weeks later. In 1998, the same area of the field and the same plots were sampled as described, and an additional 12 plots (446 $\mathrm{m}^{2}$ ) adjacent to the area used in 1997 also were sampled in 1998.

Isolation of $\boldsymbol{P}$. sojae. The soybean seedling bioassay procedure described by Schmitthenner and Bhat (25) was used to isolate $P$. sojae from soil in both the statewide collection and from the within-field variability study. The bulked soil samples were placed in 15.24-cm-diameter vinyl pots, flooded for $24 \mathrm{~h}$, and then allowed to dry slowly in the dark at room temperature until the soil began to pull away from the sides of the pots. Pots then were placed in plastic bags for approximately 2 weeks until planting. Ten soybean seed (cv. Williams) were placed on the soil surface and covered with moist vermiculite, after which the pots were placed in clear plastic bags in the growth chamber at $24^{\circ} \mathrm{C}$. At seedling emergence, the pots were removed from the bags, flooded overnight, and returned to the growth chamber. After approximately 3 days, diseased plants could be identified by the development of prominent lesions that eventually resulted in collapse of the hypocotyls.

Isolations were attempted from all symptomatic Williams seedlings in each soil sample, and each isolate was numbered and maintained as a separate culture. Entire symptomatic seedlings were surface disinfested by submersion in $0.05 \%$ so- dium hypochlorite solution, washed in distilled water, and washed in $70 \%$ ethanol (30 s in each solution). To isolate $P$. sojae, tissue from the upper leading edge of the lesions was placed on the semiselective medium PBNIC (25) containing Terrachlor (99\% pentachloronitrobenzene) at 0.04 $\mathrm{g} /$ liter, Benlate $(50 \%$ benomyl) at 0.01 $\mathrm{g} /$ liter, neomycin sulfate at $0.10 \mathrm{~g} / \mathrm{liter}$ Rovral (50\% iprodione) at $0.04 \mathrm{~g} /$ liter, and chloramphenicol at $0.10 \mathrm{~g} / \mathrm{liter}$ in a concentrated lima bean agar base. Lima bean agar was prepared by autoclaving $150 \mathrm{~g}$ of frozen lima beans in $500 \mathrm{ml}$ of distilled water. The beans were macerated through a sieve, and the extract was filtered through $1 \mathrm{~cm}$ of diatomaceous earth and Whatman filter paper. The volume of the resulting broth was increased to 1 liter using distilled water, and $20 \mathrm{~g}$ of Difco Bacto agar was added. All of the PBNIC amendments were added except Rovral. The mixture was autoclaved for $30 \mathrm{~min}$. Prior to pouring the agar into petri dishes, Rovral was partially dissolved in $2 \mathrm{ml}$ of ethanol and added to the molten agar.

The lower stems of plants collected from the plots in the within-field variability study were excised at the soil line and at the cotyledonary node and washed in dishwashing detergent under a stream of tap water for $10 \mathrm{~min}$. Each stem then was surface disinfested as described above, but with a duration of $1 \mathrm{~min}$ in each solution. Each stem was cut longitudinally and cortical tissue was removed from at least two places and placed on PBNIC agar, and the agar was inverted in the dish to minimize bacterial contamination. P. sojae that grew out of the tissue was subcultured on PBNIC and maintained on dilute lima bean agar (DLBA) containing the filtered extract of $50 \mathrm{~g}$ of lima beans per liter (25). In 1998, DLBA was replaced with Difco Bacto lima bean agar.

$P$. sojae cultures growing on the PBNIC medium were characterized by the slow growth of dense white mycelium with right-angle branching of coenocytic hyphae. Many of the isolates also were subcultured on potato dextrose agar (PDA). Cultures isolated from diseased plant tissue were identified as $P$. sojae if they possessed these morphological characteristics plus the inability to grow on PDA and abundant production of spherical oospores homothallically on PBNIC and DLBA media $(9,12,25)$. When Pythium spp. were isolated, they were easily distinguished by their faster and less dense growth on the PBNIC medium (25). The mycelium of Phytophthora sojae cultures and the agar were removed carefully and intact from the petri dish, inverted, and replaced in the petri dishes to minimize bacterial contamination. Isolates were maintained on DLBA at room temperature.

Single-zoospore isolates. A singlezoospore isolate was produced from each of the cultures using the following proce- dure. Fifteen plugs from the leading edge of a culture actively growing on DLBA were incubated in $25 \mathrm{ml}$ of sterilized lima bean broth (the filtered extract of $150 \mathrm{~g}$ of frozen lima beans) for $48 \mathrm{~h}$. The lima bean broth (LBB) was decanted off, and the plugs were washed with $25 \mathrm{ml}$ of ChenZentmyer salt solution four times at 15min intervals $(6,25,26)$. The plugs were incubated in $25 \mathrm{ml}$ of sterile distilled water for $24 \mathrm{~h}$ until zoospores were observed using a stereomicroscope, and a dilution plating series was performed on DLBA. A colony that was formed from a single zoospore was selected to represent the isolate. Single zoospore colonies were subcultured and maintained on DLBA at room temperature. A total of 32 single-zoospore isolates were collected from 23 commercial fields, and 83 single-zoospore isolates were collected from the field located on the Southeast Branch Experiment Station.

Race characterization. Hypocotyl injection was used to test each singlezoospore isolate on soybean cultivars (differentials) each containing a single Rps gene. The differentials included Harlon (Rps1a), Harosoy 13XX or L77-1863 (Rps 1b), Williams 79 (Rps1c), P. I. 103.091 (Rps $1 \mathrm{~d})$, Williams 82 (Rps $1 \mathrm{k})$, L83-570 (Rps3a), Harosoy 62XX (Rps6), and Harosoy (Rps7) (26) and were obtained from A. F. Schmitthenner and A. E. Dorrance at the Ohio Agricultural Research and Development Center in Wooster, $\mathrm{OH}$. Inoculum was prepared by macerating a 2-week-old culture on DLBA by forcing it through a 10-ml hypodermic syringe (without a needle), and then forcing it through the syringe a second time, with an 18-gauge needle attached. The macerated culture then was loaded back into the syringe and injected into a longitudinal slit $(<1 \mathrm{~cm}$ long $)$ in the hypocotyl of 10 7-day-old seedlings of each differential approximately $1 \mathrm{~cm}$ below the cotyledons.

Following inoculation, the plants were placed in a dew chamber for $24 \mathrm{~h}$ at $24^{\circ} \mathrm{C}$ to prevent desiccation of the inoculum $(15,16,25)$. Plants then were placed into a lighted growth chamber at $24^{\circ} \mathrm{C}$ on 12 -h light cycles. Symptom development was rated within 3 days after inoculation. If a cultivar exhibited $70 \%$ seedling mortality, the reaction was considered susceptible. If $30 \%$ or fewer of the seedlings of a cultivar died, the reaction was considered resistant. Seedling mortality from 30 to $70 \%$ was considered an intermediate reaction $(2,4,23,31)$. Isolates showing the same resistant or susceptible response in a minimum of two trials were characterized to race based on the virulence patterns of the 55 reported races of $P$. sojae (20). Isolates giving intermediate reactions in at least four consecutive attempts were considered unclassifiable.

Cultivar screen. Nine commercial soybean cultivars representing a range of re- 
ported resistance levels to $P$. sojae (3) were screened for resistance to races 10,15 , and 26 using hypocotyl injection and to races $10,15,24$, and 26 using an inoculum layer technique (25). Race 26 was included in these evaluations to create a more strenuous test because of its more complex virulence pattern and its pathogenic similarity to races that were frequently identified in the preliminary race survey in Arkansas. The cultivars tested included Hutcheson (susceptible to $P$. sojae), Pioneer Variety 9592 (field tolerant), Novartis NK Brand S59-60 (field tolerant), Asgrow 5885 (field tolerant), Asgrow 5403 (field tolerant), Manokin (moderately resistant), Hartz Variety 5545 (moderately resistant), Riverside 499 (moderately resistant), and Pioneer Variety 9692 (field tolerant) (3). The cultivars' disease ratings for Phytophthora root and stem rot were supplied by the seed companies.

Ten seedlings of each cultivar were inoculated by hypocotyl injection and rated as resistant or susceptible. The races of the cultures were confirmed by simultaneously inoculating the differentials and the experiment was repeated. The inoculum layer tests used $909-\mathrm{ml}$ polystyrene cups $(10 \mathrm{~cm}$ in diameter by $16 \mathrm{~cm}$ tall) with drainage holes in the bottom (14). Moistened vermiculite was added to each cup to a depth of $10 \mathrm{~cm}$, and a 2-week-old culture $(10 \mathrm{~cm}$ in diameter) grown on DLBA in the dark was removed intact from a petri dish, placed on top of the vermiculite, and covered with an additional $4 \mathrm{~cm}$ of moistened vermiculite. Eleven seed of the cultivar to be tested were placed in the center of the cup so that the emerging roots would grow through the layer of inoculum. Seed were covered with $2 \mathrm{~cm}$ of vermiculite and the cups were placed in the growth chamber at $24^{\circ} \mathrm{C}$ with 12 -h light and dark cycles (25). Cultivars were arranged in a randomized complete block design for each race, and three replications (cups) of each cultivar for each race were used. The experiments were repeated.

After 3 weeks, the plants were removed from each cup and rated as a group according to the extent of root rot and overall plant vigor using the following 1-to-10 scale: $1=$ no root rot; 2 = trace of root rot; $3=$ bottom third of root mass rotted; $4=$ bottom two-thirds of root mass rotted; $5=$ all roots rotted, $10 \%$ seedlings killed, slight stunting of tops of plants; $6=50 \%$ seedlings killed, moderate stunting of tops; $7=75 \%$ seedlings killed, severe stunting of tops; $8=90 \%$ seedlings killed; $9=$ all seedlings dead; and $10=$ all seedlings killed before emergence (25).

\section{RESULTS}

Race survey. A total of seven races, including races $1024,15,2,14,26$, and 38 (Table 1), were identified among the $32 P$. sojae isolates collected from 23 soybean fields in 14 Arkansas counties (Fig. 1;
Table 2). P. sojae race 10 was the most frequently isolated, and comprised almost half of the total isolates identified (Table 1). Race 3, the predominant race from the previous survey conducted in Arkansas, was not found. Seven isolates were identified as race 24 , with a virulence formula very similar to race 10 , and three isolates were characterized as race 15 . A single isolate each of races $2,14,26$, and 38 also was identified, and three isolates were categorized as undetermined because of inconclusive results. There was no apparent relationship between races identified and isolate collection location (Fig. 1).

All of the isolates that were successfully characterized to race were virulent on the gene Rps7 (Fig. 2A). A majority of the isolates also were virulent on Rps3a (93\%) or Rps $1 \mathrm{~b}(86 \%)$, and $31 \%$ of the isolates also showed virulence on Rps6. Fewer than $10 \%$ of the isolates exhibited virulence to the resistance genes $R p s 1 \mathrm{a}, R p s 1 \mathrm{c}, R p s 1 \mathrm{~d}$, or Rps $1 \mathrm{k}$.

Within-field variability. In all, $83 P$. sojae isolates were recovered from soil and plant samples from the single soybean field at SEREC during 1997 and 1998. The pathogen was isolated from the soil in all but three of the plots in 1997, and in all but three of the plots in the expanded area in 1998. Only 11 of the isolates were obtained from field-grown soybean plants. Virulence formulae corresponding to $7 P$. sojae races (races 1, 2, 10, 24, 26, 38, and 39) were found among these isolates (Ta-

Table 1. Races of Phytophthora sojae identified in Arkansas soybean fields, 1995 to 1998

\begin{tabular}{llc}
\hline Race $^{\mathbf{w}}$ & Virulence formula & No. of isolates $(\%)$ \\
\hline 10 & $1 \mathrm{~b}, 3 \mathrm{a}, 7$ & $15(47)$ \\
24 & $1 \mathrm{~b}, 3 \mathrm{a}, 6,7$ & $7(22)$ \\
15 & $3 \mathrm{a}, 7$ & $3(9)$ \\
2 & $1 \mathrm{~b}, 7$ & $1(3)$ \\
14 & $1 \mathrm{c}, 7$ & $1(3)$ \\
$26^{\mathrm{x}}$ & $1 \mathrm{~b}, 1 \mathrm{~d}, 3 \mathrm{a}, 6,7$ & $1(3)$ \\
$38^{\mathrm{y}}$ & $1 \mathrm{a}, 1 \mathrm{~b}, 1 \mathrm{c}, 1 \mathrm{~d}, 1 \mathrm{k}, 3 \mathrm{a}, 6,7$ & $1(3)$ \\
$\mathrm{I}^{\mathrm{z}}$ & $\ldots$ & $3(9)$ \\
Total & $\cdots$ & 32 \\
\hline
\end{tabular}

${ }^{\mathrm{w}}$ Races of single-zoospore isolates were determined following repeated inoculation of eight differential soybean cultivars.

${ }^{x}$ Races 2 to 26 are based on virulence formulae described by Schmitthenner et al. (26).

${ }^{y}$ Race 38 is based on the virulence formula described by Henry and Kirkpatrick (13).

${ }^{\mathrm{z}}$ Isolates could not be characterized to race due to inconsistent reactions following hypocotyl injection of eight differential cultivars.

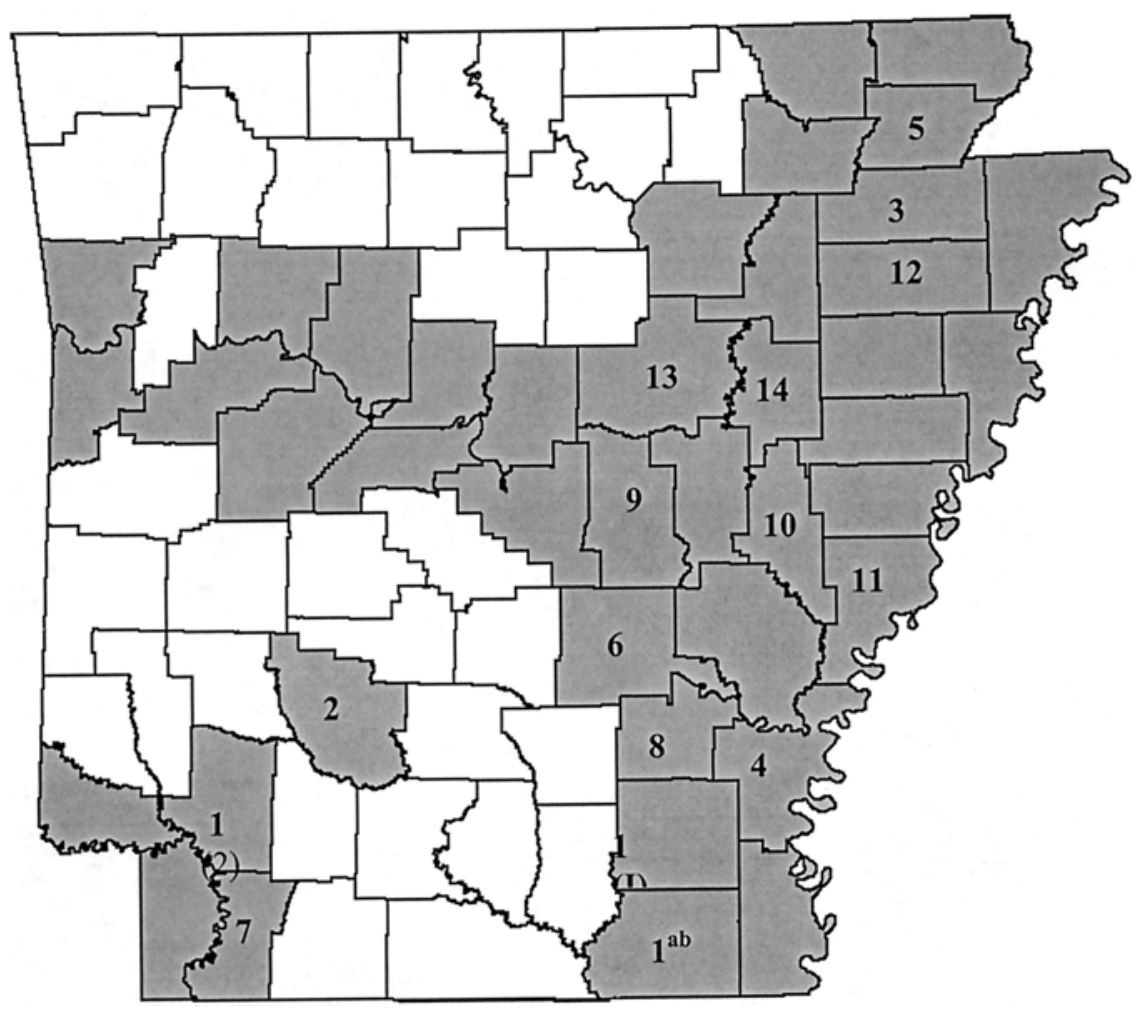

Fig. 1. Arkansas soybean-producing counties sampled for Phytophthora sojae, 1995 to 1998. Shaded counties represent the soybean-producing counties in Arkansas (18). Numbered counties represent those sampled for $P$. sojae (Table 2). 
ble 3). In addition, 20 of the isolates exhibited virulence formulae that do not correspond to any of the previously described races. These virulence formulae were consistent over multiple repetitions on the differential cultivars and have been grouped arbitrarily into virulence types A to $F$ (Table 3). The virulence formulae of 22 of the isolates recovered from this field were not characterized due to inconsistent responses on the soybean differentials. Although these isolates could not be char-

Table 2. Phytophthora sojae race distribution in soybean-producing counties in Arkansas, 1995 to 1998

\begin{tabular}{lccl}
\hline County & Fields sampled & No. of isolates & \multicolumn{1}{c}{ Race $^{\mathbf{y}}$} \\
\hline 1. Ashley & 1 & 1 & $\mathrm{I}^{\mathbf{z}}$ \\
2. Clark & 1 & 1 & 24 \\
3. Craighead & 5 & 7 & $10(3), 24(2), 15, \mathrm{I}$ \\
4. Desha & 1 & 1 & $\mathrm{I}$ \\
5. Greene & 2 & 2 & $24(2)$ \\
6. Jefferson & 1 & 4 & $10(4)$ \\
7. Lafayette & 1 & 1 & 2 \\
8. Lincoln & 1 & 1 & 14 \\
9. Lonoke & 3 & 4 & $10(4)$ \\
10. Monroe & 2 & 2 & 10,38 \\
11. Phillips & 1 & 2 & 15,24 \\
12. Poinsett & 1 & 1 & 15 \\
13. White & 1 & 1 & 10 \\
14. Woodruff & 2 & 4 & $\ldots$ \\
Total & 23 & 32 & $\ldots$ \\
\hline
\end{tabular}

${ }_{\mathrm{y}}^{\mathrm{y}}$ Races of single-zoospore isolates were determined following repeated inoculation of eight differential cultivars. Frequencies of recovery of races denoted in parentheses if greater than 1.

${ }^{\mathrm{z}}$ Reactions could not be characterized to race due to variable or inconsistent reactions following a minimum of 4 attempts.
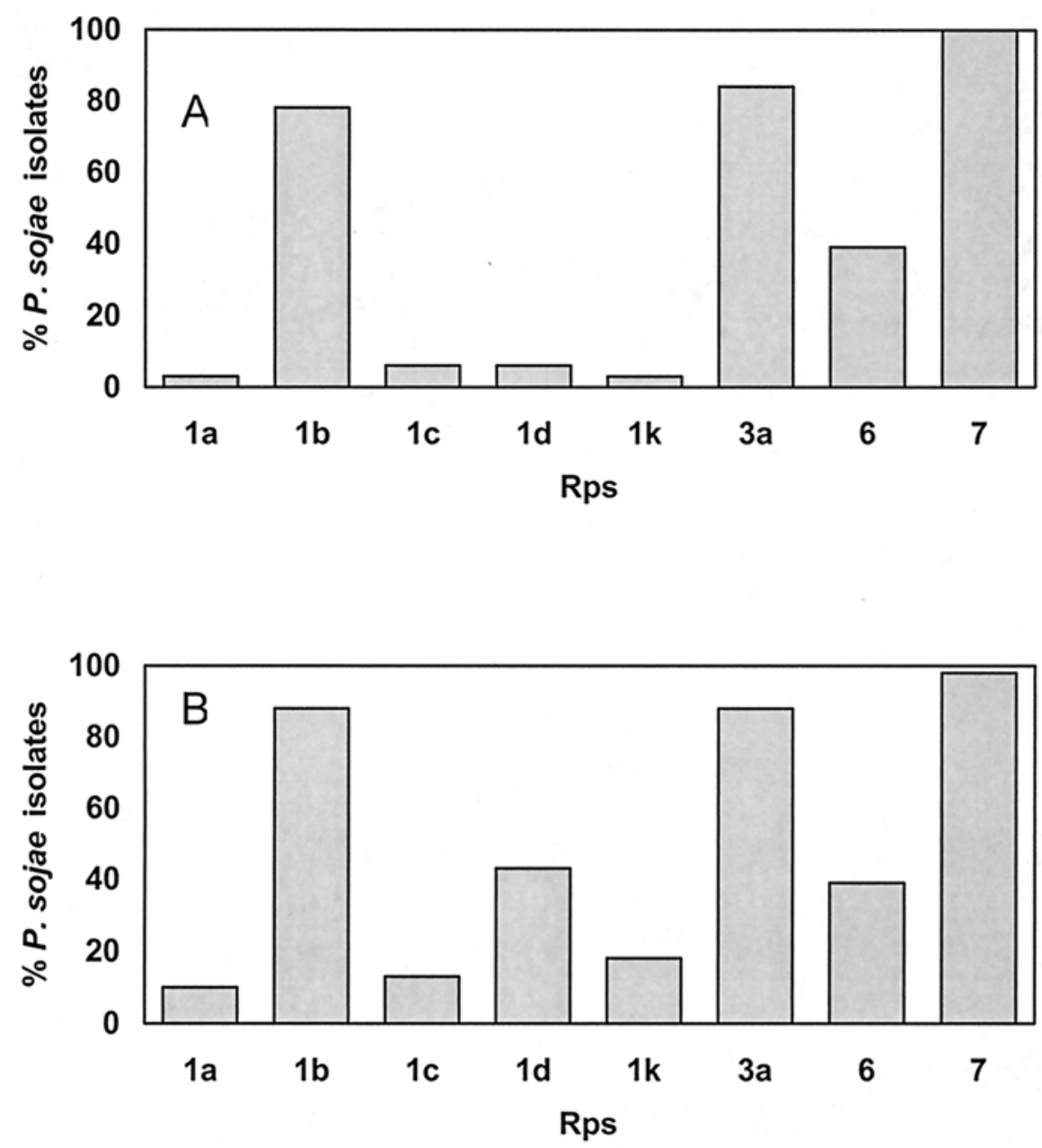

Fig. 2. Frequency of virulence of Phytophthora sojae isolates on individual Rps genes A, from soybean fields across Arkansas and $\mathbf{B}$, from a single field located at the University of Arkansas Rohwer Division of the Southeast Research and Extension Center, 1995 to 1998. Data are the percent of isolates virulent on Rps genes of the total number collected.

acterized on the eight soybean differentials, all were virulent on Rps7 and most were virulent on Rps3a and Rps1b (91 and $87 \%$ of the isolates, respectively; data not shown).

Of the 61 isolates that could be characterized, $98 \%$ contained virulence to $\operatorname{Rps} 7$ (Fig. 2B). Virulence to the genes Rps $1 \mathrm{~b}$ and $R p s 3$ a was found in $83 \%$ of the isolates. The frequency of occurrence of virulence to Rps $1 \mathrm{~d}$, Rps $1 \mathrm{k}$, and Rps6 among the isolates was 43,19 , and $30 \%$, respectively, while $13 \%$ of the isolates were virulent to either Rps 1a or Rps 1c.

Cultivar screen. There were no differences in cultivar susceptibility or resistance to $P$. sojae races 10,15 , or 26 using hypocotyl injection. Cvs. Hutcheson, Pioneer Variety 9592, Pioneer Variety 9692, Novartis NK Brand S59-60, Asgrow 5885, and Asgrow 5403 were susceptible to the isolates of all three races, while cvs. Manokin, Hartz Variety 5545, and Riverside 499 were resistant to all three races (Table 4). When these cultivars were evaluated against the same isolates using the inoculum layer technique, similar results were obtained (Table 5). In addition, cultivars that exhibited resistance or susceptibility to these races also were equally resistant or susceptible to an isolate of $P$. sojae race 24 using inoculum layering.

\section{DISCUSSION}

In contrast to the survey of $P$. sojae from Arkansas conducted in 1977, no race 3 isolates were found in our limited survey of isolates from soybean production fields in the state. Almost three-fourths of the isolates in our study were characterized as either race 10 or 24 . These races have much broader virulence formulae than race 3 , although all three are virulent on the Rps 7 gene. The virulence formulae of the races that were found throughout the state were similar, often differing from one another by virulence on only one Rps gene. This finding parallels several other reports where similar races were detected within the same regions or general areas of the country $(2,17,26,31)$. Virulence on the genes Rps1a (which also is found in race 3 isolates), Rps $1 \mathrm{c}, R p s 1 \mathrm{~d}$, and $R p s 1 \mathrm{k}$ was found at low frequencies in this study.

The variability among $P$. sojae isolates found in the single soybean field at SEREC near Rohwer, AR is interesting. For the most part, races that were identified in this site were the same as in the collection from soybean fields across the state with the exception of races 1 and 39, which were found in the single field at SEREC, but not in the limited statewide survey, and races 14 and 15 , which were found in the state collection but not in the single field at SEREC. In both cases, virulence to the genes Rps $1 \mathrm{~b}, \operatorname{Rps} 3 \mathrm{a}$, and Rps 7 was found in the majority of the isolates. 
Race changes and variations in $P$. sojae genotypes may be due to several factors. Outcrossing (11), mutations, or convergent evolution (8) all could play a role in the variability observed. Another possible explanation might be that the frequencies of occurrence of virulence formulae may have been in response to selection pressure exerted by the Rps genes that have been deployed in the field. For example, the extensive use of resistant cultivars by farmers in Wisconsin resulted in a radical change in virulence of $P$. sojae in only 2 years (27). The field at SEREC near Rohwer, AR had been used for several years prior to this study for soybean cultivar testing. It is likely that the $P$. sojae population in this particular field historically had been exposed to a more diverse array of Rps genes via a diversity of different soybean cultivars than in most production fields where only a single cultivar would normally be grown each year. In this case, the $P$. sojae population in this field would have been under more strenuous selection pressure than populations in typical grower fields. The increase in selection pressure may have driven the development of a diverse $P$. sojae population with greater genetic variability, such as the production of more races. A similar situation was observed in Australia, where there was increased genetic diversity and complexity of $P$. sojae isolates that were obtained from trial sites used for screening soybean breeding material than from isolates obtained from commercial grower fields (23). Alternatively, the genetic diversity of the $P$. sojae population in this field may be typical of populations in commercial grower fields. Sampling of grower fields seldom is conducted as extensively as it was for this test. If the extensive variability of $P$. sojae observed in this field is representative of grower fields, then current sampling and race identification procedures probably are inadequate for determining what races are prevalent and are of limited use for making cultivar recommendations because they likely underestimate the diversity of $P$. sojae.

The identification of $P$. sojae isolates at SEREC with six undescribed virulence patterns also is noteworthy because it is further evidence of the unexpected diversity of this pathogen in Arkansas. The virulence patterns of the six groups of isolates, designated as A to F in this study, do not match any of the 55 races of $P$. sojae that have been reported using the eightcultivar differential set. The virulence formula of our A group (Rps $1 \mathrm{~b}, R p s 1 \mathrm{~d}$, $R p s 3 \mathrm{a}$, and $R p s 7$ ) differs by only one gene from that of race 10 , which was the race most frequently identified from the statewide collection. Groups B, C, and D had similar virulence formulae and were most similar to reported races $12,19,20$, or 33 , which were not found in our study. Groups $\mathrm{E}$ and $\mathrm{F}$ also were very similar in viru- lence, but did not appear to correspond with any of the virulence formulae that were found in other areas of the state. These isolates probably represent new

races beyond the 55 that have been named to date. However, assignment of race designations to these virulence patterns probably is of limited value with respect to

Table 3. Virulence formulae of isolates recovered from soil and plants of a single soybean field at the Rohwer Division of the University of Arkansas Southeast Research and Extension Center during 1997 and 1998

\begin{tabular}{lcl}
\hline Race or unknown $^{\mathbf{x}}$ & No. of isolates & Virulence formula \\
\hline 1 & 3 & 7 \\
2 & 1 & $1 \mathrm{~b}, 7$ \\
10 & 13 & $1 \mathrm{~b}, 3 \mathrm{a}, 7$ \\
24 & 13 & $1 \mathrm{~b}, 3 \mathrm{a}, 6,7$ \\
26 & 8 & $1 \mathrm{~b}, 1 \mathrm{~d}, 3 \mathrm{a}, 6,7$ \\
38 & 2 & $1 \mathrm{a}, 1 \mathrm{~b}, 1 \mathrm{c}, 1 \mathrm{~d}, 1 \mathrm{k}, 3 \mathrm{a}, 6,7$ \\
39 & 1 & $1 \mathrm{a}, 1 \mathrm{~b}, 1 \mathrm{c}, 1 \mathrm{k}, 3 \mathrm{a}, 6,7$ \\
$\mathrm{~A}^{\mathrm{y}}$ & 12 & $1 \mathrm{~b}, 1 \mathrm{~d}, 3 \mathrm{a}, 7$ \\
$\mathrm{~B}$ & 2 & $1 \mathrm{~b}, 1 \mathrm{~d}, 1 \mathrm{k}, 3 \mathrm{a}, 7$ \\
$\mathrm{C}$ & 1 & $1 \mathrm{~b}, 1 \mathrm{c}, 1 \mathrm{~d}, 1 \mathrm{k}, 3 \mathrm{a}, 7$ \\
$\mathrm{D}$ & 1 & $1 \mathrm{a}, 1 \mathrm{~b}, 1 \mathrm{~d}, 1 \mathrm{k}, 3 \mathrm{a}, 7$ \\
$\mathrm{E}$ & 1 & $1 \mathrm{a}, 1 \mathrm{c}, 1 \mathrm{k}, 3 \mathrm{a}$ \\
$\mathrm{F}$ & 3 & $1 \mathrm{a}, 1 \mathrm{c}, 1 \mathrm{k}, 7$ \\
$\mathrm{I}^{\mathrm{z}}$ & 22 & $\cdots$ \\
\hline
\end{tabular}

x Races 1-26 are based on virulence formulae described by Schmitthenner et al. (26). Races 38 and 39 are based on virulence formulae described by Henry and Kirkpatrick (13).

${ }^{\mathrm{y}}$ Letters designate isolates that had undescribed virulence formulae.

${ }^{\mathrm{z}}$ Virulence formula could not be conclusively demonstrated due to inconsistent reaction on soybean differentials following repeated inoculations.

Table 4. Percent of plants of nine soybean cultivars showing symptoms after hypocotyl injection with races 10, 15, and 26 of Phytophthora sojae ${ }^{\mathrm{y}}$

\begin{tabular}{lrrr}
\hline & \multicolumn{3}{c}{ Phytophthora sojae race } \\
\cline { 2 - 4 } Soybean cultivar & $\mathbf{1 0}$ & $\mathbf{1 5}$ & $\mathbf{2 6}$ \\
\hline Asgrow 5403 (field tolerant) & 95 & 75 & 100 \\
Asgrow 5885 (field tolerant) & 85 & 85 & 100 \\
Hartz Variety 5545 (moderately resistant) & 0 & 0 & 5 \\
Hutcheson (susceptible) & 100 & 100 & 100 \\
Manokin (moderately resistant) & 0 & 0 & 10 \\
Novartis NK Brand S59-60 (field tolerant) & 100 & 90 & 100 \\
Pioneer Variety 9592 (field tolerant) & 100 & 100 & 100 \\
Pioneer Variety 9692 (field tolerant) & 100 & 100 & 95 \\
Riverside 499 (moderately resistant) & 0 & 0 & 0 \\
\hline
\end{tabular}

${ }^{y}$ Each experiment contained 10 plants and was repeated once. Data are expressed as a percent of the 20 plants total from both experiments exhibiting symptoms following inoculation.

${ }^{\mathrm{z}}$ The cultivar disease rating for Phytophthora root and stem rot from the seed company is included in parentheses (3).

Table 5. Disease severity ratings of nine soybean cultivars in response to races of Phytophthora sojae using inoculum layer ${ }^{\mathrm{x}}$

\begin{tabular}{lcccc}
\hline & \multicolumn{4}{c}{${\text { Phytophthora sojae } \text { race }^{\mathbf{y}}}$} \\
\cline { 2 - 5 } Soybean cultivar $^{\mathbf{z}}$ & $\mathbf{1 0}$ & $\mathbf{1 5}$ & $\mathbf{2 4}$ & $\mathbf{2 6}$ \\
\hline Asgrow 5403 (field tolerant) & 8.0 & 7.0 & 9.0 & 9.0 \\
Asgrow 5885 (field tolerant) & 8.5 & 7.0 & 8.0 & 9.0 \\
Hartz Variety 5545 (moderately resistant) & 2.0 & 1.0 & 1.0 & 1.5 \\
Hutcheson (susceptible) & 8.0 & 9.0 & 8.0 & 8.5 \\
Manokin (moderately resistant) & 2.5 & 1.0 & 1.0 & 1.5 \\
Novartis NK Brand S59-60 (field tolerant) & 7.5 & 8.0 & 8.0 & 8.5 \\
Pioneer Variety 9592 (field tolerant) & 8.0 & 8.0 & 9.0 & 8.0 \\
Pioneer Variety 9692 (field tolerant) & 9.0 & 8.0 & 8.0 & 9.0 \\
Riverside 499 (moderately resistant) & 1.5 & 1.0 & 1.0 & 1.5 \\
\hline
\end{tabular}

$\mathrm{x}$ Rating scale: $1=$ no discoloration; 2 = slight discoloration; $3=$ bottom third of root mass discolored; $4=$ bottom two-thirds of root mass discolored; $5=$ all root mass discolored, $10 \%$ of seedlings killed; $6=50 \%$ of seedlings killed, moderate stunting of remaining plants; $7=75 \%$ of seedlings killed, severe stunting of remaining plants; $8=90 \%$ of seedlings killed; $9=100 \%$ of seedlings killed after emergence; $10=$ all seedlings killed before emergence (25).

${ }^{y}$ Data are expressed as a mean of three replications for the repeated experiments.

${ }^{\mathrm{z}}$ The cultivar disease rating for Phytophthora root and stem rot from the seed company is included in parentheses (3). 
the improvement of management strategies for Phytophthora root and stem rot for a couple of reasons. At the time these tests were conducted, the set of 13 differential cultivars for $P$. sojae classification was widely unavailable; therefore, only the standard set of 8 was used and virulence on the additional 5 differentials is unknown. In addition, the recent move to classify $P$. sojae isolates as pathotypes instead of races is more practical because it emphasizes the virulence of the isolates (7). With regard to the six new virulence patterns detected here, greater value probably exists in the detection of more isolates that simultaneously possess virulence on multiple commonly used Rps genes, such as Rps $1 \mathrm{c}$ and $1 \mathrm{k}$. These results are important because they increase concern over the ineffectiveness of long-term use of some of these commonly deployed Rps genes in commercial cultivars and support the evidence that there is greater diversity of $P$. sojae in individual Arkansas fields than was expected.

Information on the resistance levels of the cultivars selected for the cultivar screen for resistance to $P$. sojae was supplied by the seed companies for grower use. However, the Rps genes in the cultivars were not known or were unavailable upon request, as well as the methods used to determine their levels of reported resistance. The hypocotyl injection method and the inoculum layer methods both were used in the cultivar screen in an attempt to identify both race-specific and quantitative resistance in the cultivars and to validate their reported resistance. Traditionally, the hypocotyl injection technique has been used to determine the virulence of $P$. sojae isolates following inoculation of cultivars with known Rps genes. Race designations are assigned based on published virulence patterns. Conversely, the gene-for-gene reaction exhibited by the hypocotyl injection technique has made it possible to evaluate resistance of soybean germ plasm using $P$. sojae isolates of known races (4). Because the hypocotyl injection is used to detect the presence or absence of Rps genes, cultivars were expected to be either resistant or susceptible, with no intermediate reactions. Cultivars with these genes also would be expected to have resistant ratings using the inoculum layer method. Variations of the inoculum layer technique have been used as an alternative to field testing to evaluate soybean germ plasm for tolerance to $P$. sojae $(14,28)$. The primary use of the inoculum layer method in this study was to help identify quantitative resistance (partial resistance or field tolerance) in cultivars that had susceptible reactions in the hypocotyl injection test. (The presence of Rps genes in resistant cultivars masks any evidence of quantitative resistance, making resistant cultivars poor candidates for evaluation using the inoculum layer method.) It was important to evaluate the cultivars in this test using both methods considering the lack of information available on their resistance to $P$. sojae. Cultivars clearly were either resistant or susceptible to each of the races tested using hypocotyl injection, and their reactions were consistent with seed company reports. The inoculum layer test gave similar results, however, with no intermediate responses. There was no indication that any of the cultivars tested contained quantitative resistance, although five of them were labeled as "field tolerant" by their companies. Intermediate responses were observed in the control differential sets that were run simultaneously with the test cultivars; therefore, it is likely that the cultivars rated as susceptible in the hypocotyl injection tests did not contain appreciable field tolerance to the isolates tested using the inoculum layer method. The nine commercial cultivars used in these experiments were among the most popular varieties planted in Arkansas in the mid-1990s (L. O. Ashlock, personal communication). Three of these cultivars were resistant to all of the races of $P$. sojae used, regardless of inoculation technique. Although $P$. sojae genetic variability was greater than expected, there are resistant cultivars available for planting in Arkansas.

These studies indicate that, although considerable variability in virulence appears to exist in the $P$. sojae that is present in soybean fields in Arkansas, soybean cultivars with effective levels of resistance currently are available to growers. The degree of pathogenic variability that was found in our study, however, indicates that $P$. sojae should be monitored routinely in soybean production fields across the region in order to deploy the most effective resistant cultivars for control of Phytophthora root and stem rot.

\section{ACKNOWLEDGMENTS}

We thank R. Henry for his help in collecting samples; L. Earnest and R. Cingolani of the Southeast Research and Extension Center-Rohwer Division for their help in planting and maintenance of field plots; and A. F. Schmitthenner and A. E. Dorrance for providing seed for the differential varieties and technical advice.

\section{LITERATURE CITED}

1. Abney, T. S., Melgar, J. C., Richards, T. L., Scott, D. H., Grogan, J., and Young, J. 1997. New races of Phytophthora sojae with Rps1-d virulence. Plant Dis. 81:653-655.

2. Anderson, T. R., and Buzzell, R. I. 1992. Diversity and frequency of races of Phytophthora megasperma f. sp. glycinea in soybean fields in Essex County, Ontario, 19801989. Plant Dis. 76:587-589.

3. Ashlock, L. O., Haynes, W., Coker, C., Dombek, D., Kirkpatrick, T. L., Klerk, R., and Beaty, D. 1998. Soybean Update: 1997 University of Arkansas Soybean Varietal Performance for Conventional Soybean Production Systems. University of Arkansas Cooperative Extension Service.

4. Barreto, D., Stegman de Gurfinkel, B., and Fortugno, C. 1995. Races of Phytophthora sojae in Argentina and reaction of soybean culti- vars. Plant Dis. 79:599-600.

5. Beagle, J. E., Rissler, J. F., and Kantzes, J. G. 1982. Phytophthora root rot of soybeans in Maryland. Plant Dis. 66:371-372.

6. Chen, D. W., and Zentmyer, G. A. 1970. Production of sporangia of Phytophthora cinnamomi in axenic culture. Mycologia 62:397402.

7. Dorrance, A. E., McClure, S. A., and deSilva, A. 2003. Pathogenic diversity of Phytophthora sojae in Ohio soybean fields. Plant Dis. 87:139-146.

8. Drenth, A., Whisson, S. C., Maclean, D. J., Irwin, J. A. G., Obst, N. R., and Ryley, M. J. 1996. The evolution of races of Phytophthora sojae in Australia. Phytopathology 86:163169.

9. Erwin, D. C., and Ribeiro, O. K. 1996. Phytophthora Diseases Worldwide. American Phytopathological Society, St. Paul, MN.

10. Ferguson, M. W. 1987. Epidemic of Phytophthora root rot of soybeans in South Dakota. Plant Dis. 71:850.

11. Förster, H., Tyler, B. M., and Coffey, M. D. 1994. Phytophthora sojae races have arisen by clonal evolution and by rare outcrosses. Mol. Plant-Microbe Interact. 7:780-791.

12. Hansen, E. M., and Maxwell, D. P. 1991. Species of the Phytophthora megasperma complex. Mycologia 83:376-381.

13. Henry, R. N., and Kirkpatrick, T. L. 1995. Two new races of Phytophthora sojae, causal agent of Phytophthora root and stem rot of soybean, identified from Arkansas soybean fields. Plant Dis. 79:1074.

14. Jimenez, B., and Lockwood, J. L. 1980. Laboratory method for assessing field tolerance of soybean seedlings to Phytophthora megasperma var. sojae. Plant Dis. 64:775-778.

15. Keeling, B. L. 1982. Four new physiologic races of Phytophthora megasperma f. sp. glycinea. Plant Dis. 66:334-335.

16. Keeling, B. L. 1985. Responses of differential soybean cultivars to hypocotyl inoculation with Phytophthora megasperma f. sp. glycinea at different temperatures. Plant Dis. 69:524 525.

17. Kennedy, B. W. 1984. Root rot of soybean in Minnesota: The changing race situation in Phytophthora megasperma f. sp. glycinea. Plant Dis. 68:826.

18. Klugh, B. F., and Abbe, D. S. 1996. Arkansas Agricultural Statistics for 1995. Ark. Agric. Exp. Stn. Univ. Ark. Rep. Ser. 334.

19. Laviolette, F. A., and Athow, K. L. 1981. Physiologic races of Phytophthora megasperma f. sp. glycinea in Indiana, 19731979. Plant Dis. 65:884-885.

20. Leitz, R. A., Hartman, G. L., Pedersen, W. L., and Nickell, C. D. 2000. Races of Phy tophthora sojae on soybean in Illinois. Plant Dis. 84:487.

21. Morgan, F. L., and Hartwig, E. E. 1965. Physiologic specialization in Phytophthora megasperma var. sojae. Phytopathology 55:1277-1279.

22. Nelson, B. D., and Hansen, J. M. 1996. Races of Phytophthora sojae on soybean in the Red River Valley of Minnesota and North Dakota. Plant Dis. 80:104.

23. Ryley, M. J., Obst, N. R., Irwin, J. A. G., and Drenth, A. 1998. Changes in the racial composition of Phytophthora sojae in Australia between 1979 and 1996. Plant Dis. 82:10481054.

24. Schmitthenner, A. F. 1991. Relative prevalence of races of Phytophthora sojae in Ohio during 1990. (Abstr.) Phytopathology 81:1151.

25. Schmitthenner, A. F. and Bhat, R. G. 1994 Useful methods for studying Phytophthora in the laboratory. Dep. Plant Pathol. Ohio Agric. Res. Dev. Cent. Circ. 143.

26. Schmitthenner, A. F., Hobe, M., and Bhat, R. G. 1994. Phytophthora sojae races in Ohio 
over a 10-year interval. Plant Dis. 78:269-276.

27. Tooley, P. W., Grau, C. R., and Stough, M. C. 1982. Races of Phytophthora megasperma f. sp. glycinea in Wisconsin. Plant Dis. 66:472475 .

28. Walker, A. K., and Schmitthenner, A. F. 1984. Comparison of field and greenhouse evalua- tions for tolerance to Phytophthora rot of soybean. Crop Sci. 24:487-489.

29. White, D. M., Partridge, J. E., and Williams, J. H. 1983. Races of Phytophthora megasperma f. sp. glycinea on soybeans in eastern $\mathrm{Ne}$ braska. Plant Dis. 67:1281-1282.

30. Wrather, J. A., Stienstra, W. C., and Koenning,
S. R. 2001. Soybean disease loss estimates for the United States from 1996 to 1998. Can. J. Plant Pathol. 23:122-131.

31. Yang, X. B., Ruff, R. L., Meng, X. Q., and Workneh, F. 1996. Races of Phytophthora sojae in Iowa soybean fields. Plant Dis. 80:1418 1420. 